\title{
Entrevista: Fernanda Arêas Peixoto e Maria Alice Rezende de Carvalho
}

\author{
Fernando Espósito \\ Professor do Departamento de Arquitetura e Urbanismo da PUC-Rio \\ Contato: fernando.esposito@ead.cl
}

Entrevista concedida a Fernando Espósito em 08 de julho de 2016

A Revista PRUMO teve a oportunidade de entrevistar Fernanda Arêas Peixoto, organizadora e uma das autoras de Ciudades Sudamericanas como Arenas Culturales, e Maria Alice Rezende de Carvalho, também autora do livro. O volume apresenta diversos olhares sobre a vida cultural urbana da América do Sul, todos de grande interesse, sobretudo pelo foco colocado na cidade como lugar de germinaçáo de tendências artísticas, projetos intelectuais e disputas político-ideológicas.

Como indicado pelos organizadores na apresentação do livro, o trabalho realizado lança múltiplas perspectivas sobre a vida urbana no sul do continente a partir da consideração de "episódios" de diferentes cidades, entre finais do século XIX e inícios do XXI. São Paulo, Rio de Janeiro, Buenos Aires, Recife, Montevidéu, Santiago do Chile, entre outras, são observadas por meio de recortes variados, alguns relacionados a um lugar (uma rua ou um bairro, por exemplo) e outros relacionados à produçáo cultural propriamente dita, entre as quais, obras teatrais e televisivas.

As cenas e laboratórios urbanos oferecidos por cada um dos ensaios funcionam como "dispositivos de observação" capazes de aproximar o leitor de uma das muitas camadas que compóem a cidade, sejam elas físicas, sociais e históricas, sem esquecer as dimensóes imaginativas, afetivas e memorialísticas que constituem e produzem a vida urbana.

No título do livro, a ideia de arena pode evocar a imagem de um lugar de confrontos, de choques. No entanto, a dimensáo "cultural" que a acompanha parece resgatar uma visáo mais amigável do confronto. Vocês poderiam falar dessa figura e de como o livro a apresenta, ou se desdobra, a partir dela?

FP: A imagem surge de um texto de Richard Morse no qual ele pensa a cidade precisamente como arena cultural . Essa imagem foi por nós tomada, não como mera metáfora, mas como um instrumento de análise; afinal, Morse propóe que olhemos a cidade como um espaço de embates e de criaçôes novas. Foi a partir dessa inspiração que nós autores nos envolvemos em uma reflexão sobre as relaçóes entre cidade e cultura. Como é possível capturar tais relaçôes pensando-as como relaçóes de dupla mão, de retroalimentação? Esta é a bússola analítica que orienta todos os ensaios reunidos no volume. Se não há receitas para percorrer o caminho traçado, a figura das arenas culturais nos pareceu frutífera, capaz de iluminar possibilidades originais; pensar a cidade como um espaço de germinaçáo de ideias e proposiçóes novas em diversos campos, processos marcados por embates e tensóes, este era o desafio. 
E os autores aceitaram a proposta, converteram a imagem em um instrumento reflexivo, experimentando-a de maneiras diversas. A figura da arena cultural foi, entáo, testada a partir de diferentes aproximaçóes: uma rua, um edifício, um jornal, circuitos intelectuais, bares, cafés, festivais de cinema, peças de teatro etc.

MA: O uso do termo arena descontextualizado, ou seja, sem a referência à nossa inspiração original que foi o texto de Richard Morse, pode suscitar uma compreensão um pouco equivocada, já que as cidades estão na ordem do dia exatamente pelos índices de "conflitividade" que têm apresentado em todo o mundo. A arena no sentido por nós utilizado possui um significado diferente. Estamos pensando as tensóes, mas não necessariamente as tensóes sociais e sim as tensóes presentes na ordem da imaginação, das narrativas, das experimentaçóes e, inclusive, a maneira como diferentes perspectivas analíticas lidam com a cidade. São dois planos diferentes: um remete ao conflito entre atores sociais e o outro ao conflito que funda uma reflexão; e os dois planos são igualmente importantes. Para nós, porém, nesse livro, são os experimentos da ordem da imaginação literária e sociológica que interessava enfrentar.

Isso me leva a pensar a imagem da arena relacionada à ideia de embate em um sentido positivo. Uma possibilidade de pensar a cidade como arena de debates, compreendendo tensóes, obstáculos a partir de um ângulo positivo e propositivo, que permite enxergar diversas dimensóes. Considerando que estas podem ser muitas, vemos que o livro se constrói a partir de 23 textos, produzidos por um total de 25 autores das mais diversas áreas do conhecimento, entre elas, as ciências sociais, a arquitetura, a história, os estudos culturais. Quais foram as inquietaçóes que deram início a essa pesquisa, que atravessou fronteiras disciplinares, e como foi o processo para dar origem ao livro?
FP: O livro é resultado de um processo de trabalho iniciado em 2011, mas amparado em interlocuçôes e parcerias antigas entre o Centro de História Intelectual da Universidade de Quilmes (Argentina) e universidades brasileiras, entre as quais a USP e a PUC/RJ. Quer dizer, o projeto deste livro nasce também de outros projetos que fizemos juntos, eu, Adrián, Maria Alice e alguns dos colegas presentes no volume. Se isso é verdade, estamos diante de um projeto novo, em sua concepçáo e modo de implementação. Evidentemente, os autores foram sendo convidados a dele participar em função de relaçóes pessoais e intelectuais já existentes, mas sobretudo em função da sensibilidade para o urbano que seus trabalhos anteriores revelavam. Não buscamos necessariamente especialistas nas cidades, embora eles também estejam presentes. Há arquitetos, por exemplo, mas eu diria que um tipo particular de arquiteto que os perfis do José Lira, Adrián Gorelik e Guilherme Wisnik permitem entrever: aqueles envolvidos com a história, a crítica da arte e da cultura, e de clara vocação interdisciplinar. Reunimos, assim, pessoas que já trabalhavam com temas urbanos e outras que se não trabalharam diretamente sobre as cidades mas indicavam interesse por elas, perceptível nas reflexôes que empreenderam antes. Mas, vale sublinhar, todos produzimos reflexôes inéditas para o projeto, ensaiamos perspectivas novas em função das demandas feitas e das discussóes realizadas durante a elaboração dos ensaios.

Sobre o modo como atravessamos as fronteiras disciplinares com a ajuda dos colegas de vários campos do conhecimento, que se refere à segunda parte de sua pergunta. Não parece demais lembrar que a cidade é um objeto complexo e que o enfrentamento das relaçóes entre cidade e cultura - que nos conduz à cidade praticada, imaginada, produzida e consumida - nos colocava diante de uma tarefa da qual, dificilmente, um especialista poderia dar conta. A constituição de um grupo com formaçóes variadas foi o que permitiu o projeto e o 
seu êxito. Cada um de nós, com seus instrumentos e suas histórias profissionais específicas, acabou manejando a figura da arena cultural desde um ângulo próprio, iluminando um aspecto das relaçóes entre vida urbana e criação cultural.

MA: Chamaria a atenção para algo que também nos preocupava desde a origem do projeto (ou pelo menos preocupava a alguns de nós), que diz respeito ao fato de as cidades sul-americanas náo serem mais passíveis de uma representação sintética, comum a todas, tal como ocorria até os anos de 1960/1970. Naquela época, a expressão "cidades sul-americanas" era uma espécie de senha para o tratamento de temas muito vastos, como, por exemplo, o do subdesenvolvimento. Ou seja, predominava uma agenda cognitiva e política que lidava com a cidade entendida como um dos elementos que compunha o contexto da modernização periférica. É a partir dos anos 80 do século passado que a cidade começa a ganhar autonomia, começa a se tornar uma "variável independente" - e Morse foi decisivo nesse processo de conferir alma à cidade.

Portanto, quando da realização desse livro, sabíamos que seria necessário escapar daquela forma antiga (mas ainda influente em alguns círculos) de tratamento das cidades sul-americanas. Queríamos testar abordagens, recortar objetos, reconstruir analiticamente as cidades, porém com outros óculos. Inclusive porque os narradores da cidade, nesse início do século XXI, são em maior número e mais diversificados do que os do século passado. Índios nas cidades andinas, moradores de favelas no Rio de Janeiro, estudantes universitários nas cidades-campi são autorais, "produzem" a cidade em que vivem e sobre a qual escrevem. Então era sobre isso que queríamos falar e o livro nasceu de preocupaçóes que têm a ver com esse percurso, percurso que cada um de nós conheceu mais ou menos de perto.

$\mathrm{Na}$ apresentação do livro feita no Instituto Moreira Salles, ficaram claras a riqueza e motivaçóes do projeto. Percebe-se que não há a intençáo de impor uma ideia, mas a proposta de olhar a cidade desde diversas disciplinas. Cada capítulo apresenta, assim, uma espécie de "dispositivo" para olhar a cidade que toma a forma de narrativas que visibilizam, por exemplo, o morador de rua e a própria rua, possibilitando enxergar a cidade também em sua materialidade. Outra característica do livro é a forma de pensar os processos urbanos temporalmente, como cronologias da cidade. Isso porque as escolhas apontam para uma divisáo temporal, que abrange casos desde 1910 até praticamente 2010. Ao lado disso, existe um recorte espacial perceptível nas cidades escolhidas, embora eu mesmo desconheça o critério de escolha. Mas cidades como Buenos Aires, Sáo Paulo e Rio de Janeiro se repetem em mais de um texto. Qual a intençáo de organizar o livro dessa forma? De que maneira essa ordem de tempos e cidades foi planejada?

FP: Além de tomarmos a figura das arenas culturais como instrumento analítico fundamental, como dissemos, elegemos alguns momentos-chave como balizas para as análises. Tais divisóes temporais, como você diz, forneceram parâmetros para que pudéssemos pensar como, em alguns períodos, as relaçóes entre cidade e cultura se apresentaram de maneira particular: a passagem do século XIX para o XX; os anos 1910-1930; os anos 19401970; os anos 1990-2010. A hipótese norteadora dessas escolhas, como eu e Adrián escrevemos na introdução, esteve orientada pela seguinte indagação: seria possível reconhecer momentos determinantes nos quais as relaçóes entre cidade e cultura teriam se apresentado de forma particularmente produtiva? E, como você bem observou, esses períodos acabaram funcionando como patamares de observaçáo para o exame da trama dessas relaçóes, a cidade se revelando de diversos modos: na sua materialidade, na sua história e em função da produção cultural, 
entendida em sentido amplo. Mas o livro não é uma história das cidades da América Latina, nem tampouco uma obra de consulta. Náo se trata de buscar nos capítulos sobre Córdoba ou sobre Quito, por exemplo, informaçóes a respeito das cidades, não é esse o propósito. Os marcos temporais funcionaram com parâmetros reflexivos, como outro instrumento de análise e composição. Menos do que desenhar uma linha cronológica ou uma história, eles serviram como pontos de apoio para que lançássemos uma reflexão sobre a mútua produçáo da cidade e da cultura.

Em relação à escolha das cidades, havia cidades que, naturalmente, não podíamos deixar de fora do projeto, e nos demos conta, também, que algumas delas deveriam figurar mais de uma vez, como Rio de Janeiro, São Paulo e Buenos Aires. Mas por que Santiago não figurou em diferentes épocas? $\mathrm{Ou}$ por que Belém não foi contemplada? São lacunas, evidentemente, ainda que o propósito, insisto, não fosse realizar uma obra exaustiva. Assim que, a partir de alguns consensos básicos, fomos tentando encontrar pessoas que aceitassem o desafio central do projeto, concordando em produzir uma reflexão inédita a partir dele. E nem sempre encontramos essas pessoas, e isso não porque elas não existam, mas porque trabalhamos no interior de redes mais ou menos conhecidas, como sempre ocorre, redes que embora fossem se alargando ao longo do processo de trabalho nem sempre permitiram preencher certos vazios. Mas, volto a dizer, não se tratava de dar conta das cidades sul-americanas na sua integralidade, mas de pensar casos e situaçôes, pensando-os, lado a lado, de modo que um exemplo pudesse rebater e ecoar no outro.

MA: O que esse livro ensina, entre outras coisas, é que é possível construir uma coletânea em moldes mais orgânicos, ainda que seus autores morem em países diferentes e sejam muitos. Nas coletâneas, em geral, o organizador sabe, de antemáo, que temas gostaria de ver reunidos e convida pesquisadores adequados ao seu projeto. No livro organizado por Adrián e Fernanda o desenho do projeto conheceu um andamento distinto: havia uma intenção original que, após muitos encontros e conversas, foi adquirindo uma forma. Realizamos alguns seminários que tiveram grande importância na definição dessa modelagem final. $\mathrm{O}$ volume, portanto, não foi organizado tendo por base um mapa de navegação dado a priori. Ele foi sendo construído e, no percurso, houve também desistências, pessoas que não conseguiram atender os prazos, alguns eventos que obrigaram autores e editores a fazer ajustes.

Quando vocês falam do processo de trabalho, dos encontros e seminários como espaços de exercício e experimentaçáo, fica claro que se tratou de uma metodologia: ir encontrando o material a partir da pesquisa dos autores (eles mesmos em processos de descoberta), e posteriormente organizá-lo de forma coerente com o que se discutia. Assim, parece não ter havido um roteiro fixo predeterminando esse caminho.

FP: Só para complementar o que disse a Maria Alice sobre as coletâneas, e sem desmerecer as coletâneas existentes (há diversas que são excelentes), quando somos convidados a delas participar, em geral, reaproveitamos pesquisas e textos que já possuímos. No caso deste livro, nós efetivamente produzimos reflexóes novas, motivados pelo projeto inicial. Nesse sentido, o livro não reúne estudos existentes sobre cidades da América Latina, mas é fruto de um desafio intelectual proposto a profissionais que, de algum modo, já exercitavam em seus trabalhos anteriores uma perspectiva urbana sobre os estudos culturais. A intenção era tirar a cidade do pano de fundo, trazendo-a para o primeiro plano e pensando-a em sua articulação íntima e inextrincável com a cultura, em certos momentos-chave.

E para voltar à sua observação, Fernando, o projeto primeiro tinha sim diretrizes e coordenadas, mas elas foram sendo testadas, redefinidas e 
calibradas em função das pesquisas e das discussóes sistemáticas realizadas sobre as primeiras versões dos ensaios que fizemos ao longo do processo de trabalho.

Os autores apresentam as diferentes cidades no livro a partir de episódios (o que antes chamamos de "dispositivos para olhar a cidade") ocorridos em cada uma delas. Nesse sentido, a cultura, aparentemente, é compreendida em relaçáo à construçáo do cotidiano, à interpretaçáo da cidade como espaço de encontros. Percebo que a escolha dos autores, ao falar desses "episódios" como vocês denominam, tem a intençáo de gerar uma proximidade com uma determinada situação e cena urbana analisada. Sendo assim, qual é o papel da cultura na interpretaçáo do espaço urbano e sua relaçáo com a imagem da arena?

MA: Em função de nossas formações variadas, a noção de cultura possui inclinaçôes e assentamentos diferentes para cada um de nós. O antropólogo, por exemplo, jamais fala em cultura no singular, mas em culturas no plural. O sociólogo, por sua vez, prefere o singular, porque tem a pretensão de produzir uma visada mais sintética. Beatriz Jaguaribe, outra autora do livro e crítica da cultura, diz que a cidade hoje é muito mais disputada, mista e mesclada do que já foi. Ela lembra, por exemplo, que, embora no século XIX proliferassem distintas narrativas sobre a rua, é apenas hoje que a autoria dessas falas compete a todos os tipos de transeunte, mesmo os mais pobres e marginalizados, e náo apenas aos literatos. Estamos, pois, diante de uma cultura em mudança, que se democratizou e que produz formas de entendimento da cidade muito diferentes entre si. Isso, de um lado. Do ponto de vista das ciências sociais, a coisa é ainda mais complicada. Porque para os cientistas sociais não interessa apenas o embate de narrativas, mas também as narrativas teóricas sobre a cidade. Como uma determinada teoria interacionista, atenta a encontros, constrói a cidade? Como uma teoria da estruturação, interessada na morfologia urbana, constrói a cidade? Estamos falando, também aí, de um padrão de cultura, de um padrão de cultura acadêmica que se projeta sobre a compreensão da cidade. Assim que ao longo da elaboraçáo de nossos ensaios percebemos que o que a cultura projeta no entendimento da cidade varia em razão das tradiçóes distintas a que estamos referidos. Cada um de nós, afinal, consulta a sua tradição. A minha, por exemplo, como socióloga, remonta ao século XIX; a de um filósofo político remontaria ao Renascimento ou antes ainda; os antropólogos recuariam, provavelmente, à passagem do século XIX ao XX. Enfim, a nossa cultura disciplinar é revisitada cada vez que nos deparamos com um objeto. E com a cidade não seria (e não foi) diferente.

FP: A Maria Alice respondeu magnificamente. Só gostaria de acrescentar um ponto. Acho que o livro também está interrogando a própria categoria de cultura urbana. O que que é isso que chamamos de cultura urbana? Evidentemente, cada autor está interrogando essa categoria de um lugar, mas, insisto, creio que um dos méritos do livro é interpelar as próprias categorias, não só a de cultura urbana, mas também a de modernidade e mesmo a de cidade. Em relação à cultura e à produção cultural, estamos falando de produçóes cultas e "eruditas", mas também de práticas cotidianas, da indústria cultural, da música popular e da cultura acadêmica. Falar em cultura urbana e em produção cultural urbana é se referir a tudo isso e, talvez, a mais alguma coisa. Creio que esta é mais uma contribuição do volume.

O livro, como já foi dito, trata de várias cidades, como Montevidéu, Santiago do Chile, Córdoba, La Plata, Buenos Aires, entre outras. Portanto, existe uma interessante diversidade geográfica, o que leva, também, a uma rica diversidade cultural. No entanto, cada uma, evidentemente, possui suas particularidades. Mas as temáticas (e voltando ao tema dos "episódios", ou o que chamamos anteriormente de "olhares"), também 
são muito diferentes. Como vocês avaliam essa diversidade? Sentiram falta de alguma outra cidade que poderia ter entrado na discussáo? Consideram que essa diversidade gerou um panorama suficientemente abrangente em relaçáo ao que é a nossa cultura sul-americana urbana? Existiram surpresas ao longo da pesquisa e do processo, dos encontros entre os autores, dos exercícios e das experimentaçóes? Talvez, além de inserir alguma outra cidade, ter inserido alguma outra categoria, algum outro episódio ou algum outro prisma de observaçáo da cidade. Porque, se por um lado, o objetivo náo era inserir todas as cidades sul-americanas no volume, por outro, as categorias e os episódios poderiam ser infinitos, certo? De fato, durante a apresentaçáo do livro no Instituto Moreira Salles, me lembrei da cidade onde estudei Arquitetura, Valparaíso, no Chile. Imaginei Valparaíso a partir da perspectiva dos estudantes. Esse poderia ser um episódio, um “dispositivo” de observaçáo da cidade de que falávamos no início.

MA: Fernando, nesse sentido, eu acho que muita coisa deve ter ficado de fora e a questáo, me parece, foi de certo modo respondida na apresentação do livro. Mas para quebrar a ideia de "América do Sul", de "cidades latino-americanas" ou "sul-americanas", teria sido muito útil se tivéssemos abordado a "Paris latino-americana", a "Nova York latino-americana" ou a "Miami latino-americana"...

FP: E nós queríamos fazer exatamente isso, a ideia fazia parte do projeto original.

MA: Íamos fazer isso, mas não foi possível. Se o plano inicial fosse realizado, talvez ficasse mais clara a articulação entre cultura e espaço, cultura e territorialidade, cultura e cidade...

FP: Subvertendo a geografia...

MA: Subvertendo a geografia, exatamente, e chamando a atenção para o fato de que, na verdade, a cidade sul-americana é uma perspectiva. E como perspectiva, ela pode estar em Miami ou em Paris. Esse pulo-do-gato que, infelizmente, não pode ser dado, teria deixado claríssima a nossa intenção. Se acho que ela está clara, teria ficado ainda mais evidente.

Ficou muito claro. E de fato, quando pergunto se "faltou" algo, alguma cidade, alguma categoria, náo quero dizer que percebo o projeto como incompleto, pelo contrário. Fiz a pergunta, na verdade, por curiosidade. Identifiquei-me com esse exercício e, na hora, pensei na minha cidade natal, do ponto de vista dos estudantes, como disse antes, porque, acredito, seja outra Valparaíso, diferente das muitas Valparaísos que, certamente, podem ser narradas.

FP: A lacuna assinalada pela Maria Alice talvez tenha sido a grande lacuna do projeto do ponto de vista das nossas intençóes primeiras, pois pensar as cidades latino-americanas descoladas da geografia - essas "cidades latino-americanas" que se constituíram fora do mapa - auxiliaria a deslocar a perspectiva sobre as cidades e sobre a própria América Latina. $\mathrm{O}$ que não quer dizer que não tenhamos pensado em outras dimensóes que terminaram não contempladas. A universidade de Brasília e sua relação com a cidade é outra delas. A universidade como um agente e um ator fundamental na vida urbana se faz presente em vários dos ensaios. A experiência da universidade de Brasília teria sido uma ótima contribuição, pensamos nela e, por uma série de razóes, não conseguimos inclui-la.

Simplificando bastante, é possível observar que, de forma geral, a cidade é um contexto que se configura a partir de duas dimensóes principais. A primeira, uma racionalidade que se expressa na tentativa de organizar e planejar o espaço, e a segunda, a tradiçáo e a cultura, que se expressam como interpretaçóes, apropriaçóes e usos da cidade, dimensão que, muitas vezes, não é reconhecida pela primeira e vice-versa. No livro, 
a diversidade de olhares e de episódios tratados trazem essa ideia de valorização da experiência urbana, da vivência, da autenticidade do local versus a racionalidade espacial. É nesse encontro, ou desencontro, entre o esforço por organizar e planejar e a experiência cidadá e urbana, que a arena cultural se apresenta? Como vocês veriam a relaçáo, aparentemente antagônica, entre o planejado, de um lado e, de outro, o uso, a experiência e a vivência urbana?

FP: Eu não acredito nessa dicotomia, na oposição entre a racionalidade do planejador e a experiência do usuário, analiticamente falando. Sem desconsiderar as diferenças aí implicadas, inclusive de escala, me parece fundamental superar essas dicotomias. $\mathrm{E}$ os ensaios reunidos no livro contribuem nessa direção, na medida em que mostram, pela análise detida de casos, que os projetos modernos assumiram feiçóes particulares, muito distintas entre si. Além disso, indicam como esses projetos de modernização produzem alteridades, que recebem nomes diferentes: pode ser "o campo", pode ser "o estrangeiro", "o índio", pode ser o léxico popular das ruas, ou o "passado". Mas esses outros não são antagônicos ao polo primeiro - ao "moderno" - mas são por ele produzido. Assim que há uma solidariedade, uma inseparabilidade, entre esses termos. Superar essas dicotomias do ponto de vista analítico, não significa desconhecer diferenças entre as dimensôes, igualando-as, mas visa tentar encontrar outros lugares de onde olhar e analisar o que são os projetos de modernização: projetos abortados, redefinidos em função de seus modelos, realizados de forma mais ou menos bem sucedida etc. Tais projetos são inseparáveis da produção, sistemática e permanente, dessas alteridades variadas que os constituem, e que não são, de modo algum, exteriores a eles.

MA: Gostaria de dar um exemplo nessa mesma direção e, tomando a última parte da resposta da Fernanda, que me parece muito importante. Foi no final do século XIX e começo do século XX, quando já se esboçavam as reformas de racionalização urbanística promovidas por Pereira Passos no Rio de Janeiro, que emergiu a figura de uma Rua do Ouvidor suja, boêmia e popular. Em outras palavras, o moderno produziu o seu "outro" - este é o ponto para o qual a Fernanda estava chamando a atenção. Além disso, Fernando, reconheço na sua questáo uma conotação um tanto negativa conferida à racionalidade planejadora (risos). Estou certa? Acho que a crítica atual ao projeto moderno tem demonstrado certo desprezo ao planejado, o que me parece politicamente inábil nesse contexto em que as grandes empresas de construção civil (no Brasil, mas não apenas aqui) querem exercer suas atividades com total autonomia e nenhum limite. E o projeto é sempre um limite, não?

Quanto ao ponto que você levantou sobre o "espírito" dessa coletânea, gostaria de fazer uma observação. Trata-se de uma coleção de ensaios de aproximadamente 15 laudas, que ocupam, cada um, apenas nove ou 10 páginas do livro, abordando temas muito complexos. Uma missão, portanto, difícil. Otávio Paz tem, sobre o ensaio, sobre essa forma expressiva, uma bela e esclarecedora definição. Ele diz que o ensaio trata do que, a princípio, conhecemos comunitariamente, mas não necessariamente conseguimos traduzir. $\mathrm{O}$ ensaio, portanto, bem-sucedido, é aquele que restaura nossa conexão com uma linguagem comum, com um tema comum, sabido por todos. Esse é o jogo do livro: recompor o conhecimento comunitário sobre cada cidade a partir de uma única ideia. Uma pequena ideia, um tiro curto - o ensaio é um convite à cumplicidade. E foi com a ajuda dessa forma expressiva sui generis que é o ensaio que (re)descobrimos eventos, pontos, encontros, momentos, espaços, obras, paisagens etc.

O seu comentário leva a uma conexáo especial com o arquiteto. Porque ele observa e projeta objetos, prédios, mas, também, formas e espaços que abrigam usos, lugares, para uma ou várias pessoas. $\mathrm{O}$ livro permite a possibilidade de 


\section{pensar a cidade através de um...}

FP: De um episódio.

De um episódio, exatamente. Porque o arquiteto é formado para projetar lugares, entáo, nesse ato de pensar lugares, o episódio surge como um mecanismo para se encontrar com o contexto da intervenção.

FP: Sim. E para acrescentar algo ao que disse a Maria Alice sobre o ensaio como forma, gostaria de observar que os ensaios que compóem o livro são experimentos com materiais diferentes. Isso me parece fundamental. Cada um de nós escolheu um material, fossem obras literárias, fossem imagens, festivais de cinema, mapas, peças de teatro, jornais, não importava. E, de novo, não se tratava de aplicar uma grade teórica que domesticasse esses materiais, mas se tratava, justamente, de experimentá-los, analiticamente, de modo que eles deixassem ver o tramado das relaçôes entre cidades e cultura em um momento específico. Acho que esse foi o nosso esforço e, por isso, foi táo importante para nós como exercício e como aprendizado. $\mathrm{E}$ ao leitor abre-se a possibilidade de percorrer nossos experimentos de diversos modos, comparando os exemplos tratados em função de temas, períodos e problemas, seguindo ou subvertendo a ordem proposta pelo índice do livro. As leituras variadas que serão feitas, esperamos, abrirão outras indagaçóes e desenharão novos caminhos.

\section{Referências Bibliográficas}

1. GORELIK Adrián, PEIXOTO Fernanda Arêas (Org.). Ciudades sudamericanas como arenas culturales. 1ed. Buenos Aires: Siglo XXI Editores, 2016

2. MORSE, Richard M. As cidades "periféricas" como arenas culturais: Rússia, Áustria, América Latina. In: Revista Estudos Históricos, v. 8, n. 16, p. 205-226, 1995. Publicado originalmente em Journal of Urban History, vol. 10, no 04, ago. 1984. Tradução de Francisco de Castro Azevedo, e revisão de Dora Rocha e Gilberto Velho.
3. No dia 7 de julho de 2016 o Instituto Moreira Salles do Rio de Janeiro (em parceria com o CENTRAL Núcleo de Estudos e Projetos da Cidade, do Centro de Ciências Sociais da PUC-Rio) promoveu uma mesa-redonda intitulada Cidades sul-americanas como arenas culturais, com a presença do arquiteto argentino Adrián Gorelik, diretor do Centro de História Intelectual da Universidad de Quilmes, e da antropóloga brasileira Fernanda Arêas Peixoto, professora do Departamento de Antropologia da Universidade de São Paulo com mediação de Ana Luiza Nobre (IMS/PUC-Rio). 
Ciudades sudamericanas como arenas culturales.

Artes y medios, barrios de élite y villas miseria, intelectuales y urbanistas: cómo ciudad y cultura se activan mutuamente.

Por Adrián Gorelik e Fernanda Arêas Peixoto (orgs.)

Siglo XXI Editores, Argentina, 2016.

Edição em espanhol.

Brochura, 464 p. $15 \times 23$.

ISBN: 978-987-629-639-7.

Autores: Ana Clarisa Agüero, Gonzalo Aguilar, Pablo Ansolabehere, Alexandre Araújo Bispo, Fernanda Arêas Peixoto, Anahi Ballent, Gonzalo Cáceres, Lila Caimari, Ximena Espeche, Paulo César Garcez Marins, Gustavo Guerrero, Adrián Gorelik, Beatriz Jaguaribe, Eduardo Kingman Garcés, Nísia Trindade Lima, Germán Rodrigo Mejía Pavony, Jorge Myers, Julia O’Donnell, Heloisa Pontes, Maria Alice Rezende de Carvalho, Silvana Rubino, José Tavares Correia de Lira, Gustavo Vallejo, Tamara Rangel Vieira e Guilherme Wisnik.

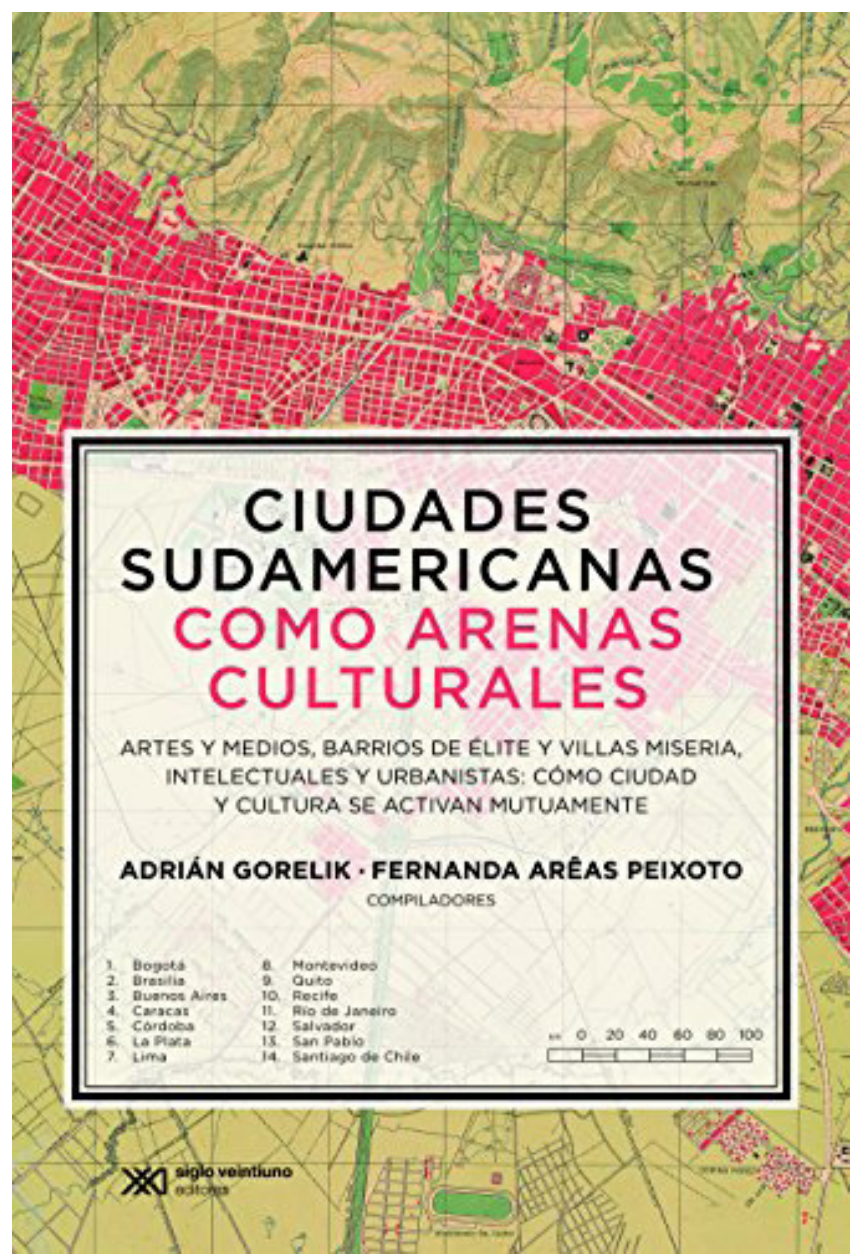

